\title{
Variations of the tautomeric preferences and $\pi$-electron delocalization for the neutral and redox forms of purine when proceeding from the gas phase (DFT) to water (PCM)
}

\author{
Ewa D. Raczyńska • Beata Kamińska
}

Received: 5 December 2012 / Accepted: 16 June 2013 /Published online: 7 July 2013

(C) The Author(s) 2013. This article is published with open access at Springerlink.com

\begin{abstract}
Quantum-chemical calculations were performed for all possible nine neutral tautomers of purine and their oxidized and reduced forms in water $\{\mathrm{PCM} / / \mathrm{DFT}(\mathrm{B} 3 \mathrm{LYP}) /$ 6 $-311+\mathrm{G}(\mathrm{d}, \mathrm{p})\}$ and compared to those in the gas phase $\{$ DFT(B3LYP $/ 6-311+\mathrm{G}(\mathrm{d}, \mathrm{p})\}$. PCM hydration influences geometries, $\pi$-electron delocalization, and relative energies of purine tautomers in different ways. Generally, the harmonic oscillator model of electron delocalization (HOMED) indices increase when proceeding from the gas phase to aequeous solution for the neutral and redox forms of purine. Their changes for the neutral and oxidized tautomers are almost parallel to the relative energies showing that aromaticity plays an important role in the tautomeric preferences. Tautomeric stabilities and tautomeric preferences vary when proceeding from the gas phase to water indicating additionally that intra- and intermolecular interactions affect tautomeric equilibria. The tautomeric mixture of neutral purine in the gas phase consists mainly of the N9H tautomer, whereas two tautomers (N9H and N7H) dominate in water. For oxidized purine, N9H is favored in the gas phase, whereas N1H in water. A gain of one electron dramatically changes the relative stabilities of the $\mathrm{CH}$ and $\mathrm{NH}$ tautomers that $\mathrm{C} 6 \mathrm{H}$ and $\mathrm{C} 8 \mathrm{H}$ dominate in the tautomeric mixture in the gas phase, whereas $\mathrm{N} 3 \mathrm{H}$ in water. These variations show exceptional sensitivity of the tautomeric purine system on environment in the electron-transfer reactions.
\end{abstract}

Keywords DFT $\cdot$ HOMED indices $\cdot$ Neutral and redox forms $\cdot$ PCM $\cdot$ Prototropy $\cdot$ Purine

Electronic supplementary material The online version of this article (doi:10.1007/s00894-013-1926-5) contains supplementary material, which is available to authorized users.

E. D. Raczyńska $(\bowtie) \cdot$ B. Kamińska

Department of Chemistry, Warsaw University of Live Science

(SGGW), 02-776 Warszawa, Poland

e-mail: ewa_raczynska@sggw.pl

\section{Introduction}

Many natural molecules, important for life, possess purine - the bicyclic heteroatomic system with the pyrimidine and imidazole rings [1,2]. For example, purine is present in nucleic acids, DNA and RNA. It is a part of nucleobases, adenine and guanine. It is also a parent system of hypoxantine, xantine, and uric acid - the products of nucleobases degradation. Alcaloids such as theophiline, theobromine, and caffeine contain also heterobicyclic purine. Most of these natural molecules, similar to unsubstituted purine, exhibit prototropic tautomerism [1-6], the intramolecular conversion which affects their structure, and chemical and biochemical properties. Understanding the mechanisms of biochemical transformations, particularly those for nucleic acids (replications, mutations, and repair), first requires an understanding of tautomerization for building blocks and an understanding of all possible factors which may influence the tautomeric equilibria.

For tautomeric system purine (Fig. 1), one proton can move between four endo-nitrogens and five endo-carbons. Each intramolecular proton-transfer is accompanied by migration of $\pi$ electrons. The amine-imine and imine-enamine tautomeric conversions lead to nine prototropic tautomers (P1-P9), four $\mathrm{NH}(\mathrm{N} 1 \mathrm{H}, \mathrm{N} 3 \mathrm{H}, \mathrm{N} 7 \mathrm{H}$, and $\mathrm{N} 9 \mathrm{H})$ and five $\mathrm{CH}$ forms $(\mathrm{C} 2 \mathrm{H}, \mathrm{C} 4 \mathrm{H}, \mathrm{C} 5 \mathrm{H}, \mathrm{C} 6 \mathrm{H}$, and $\mathrm{C} 8 \mathrm{H})$. The majority of structural studies for purine have been focused on the amine-imine tautomeric conversions for the neutral NH tautomers [1-31]. The following conclusions have been formulated. Crystal neutral purine prefers the $\mathrm{N} 7 \mathrm{H}$ tautomer due to strong intermolecular interactions [7]. Applications of the inelastic neutron scattering (INS) and Raman spectroscopy to solid purine [8] confirmed the preference of the $\mathrm{N} 7 \mathrm{H}$ tautomer. These spectroscopic investigations have been performed in parallel to DFT calculations. Much better agreement has been found with a periodic DFT calculation using the complete unit cell that explicitly includes the intermolecular interactions, in particular, the hydrogen bonding and the factor group 
Fig. 1 Prototropic tautomers for purine (the labile proton marked in bold)<smiles>C1=Nc2ncc3[nH]cc(n23)N1</smiles>

P1 (N1H)<smiles>[C]1N=CC=NC=N1</smiles>

P4 (C4H)<smiles>c1ncc2[nH]cnc2n1</smiles>

P7 (N7H)<smiles>[CH]1N=CC2=NC=NC2=N1</smiles>

P2 (C2H)<smiles></smiles>

P5 (C5H)<smiles></smiles>

P8 $(\mathrm{C} 8 \mathrm{H})$<smiles>c1c[nH]c2ncnc-2n1</smiles>

P3 (N3H)<smiles></smiles>

P6 (C6H)<smiles></smiles>

splitting, than for the isolated molecules of the N7H and N9H tautomers. However, the infrared (IR) and Raman spectra of solid purine, including isotopic derivatives, showed additionally small amounts of the N9H tautomer [9]. An existence of the $\mathrm{N} 7 \mathrm{H}$ or $\mathrm{N} 9 \mathrm{H}$ tautomers has also been postulated on the basis of the IR spectral differences using an innovative sampling technique [10]. To observe the spectra for separated solid sample molecules at room temperature, a procedure of dissolution, spray, and deposition (DSD) has been applied to neutral and acidic aqueous solutions of purine. The IR spectra obtained from neutral and acidic solutions were different. The spectral differences have been interpreted in terms of existence of the N7H (DSD acidic solution) and N9H tautomer (DSD neutral solution). The protonated form of adenine has not been considered. In solvents of medium polarity and in water, neutral purine seems to exist as a mixture of the $\mathrm{N} 7 \mathrm{H}$ and $\mathrm{N} 9 \mathrm{H}$ tautomers. This coexistence has been observed in the UV [11], NMR [12-15], IR and Raman spectra [16, 17], and investigated by quantum-chemical methods [18-20]. In aqueous solutions at room temperature, there are approximately equal amounts of the $\mathrm{N} 7 \mathrm{H}$ and $\mathrm{N} 9 \mathrm{H}$ tautomers.

Some contradictory results have been obtained with the matrix isolation techniques [21-27]. Radchenko and coworkers [21] concluded on the basis of the IR spectra of isolated purine molecules in argon matrix that the $\mathrm{N} 7 \mathrm{H}$ and $\mathrm{N} 9 \mathrm{H}$ tautomers coexist in approximately equal proportions, whereas Kwiatkowski and co-workers [22-26] and also Adamowicz and co-workers [27] using the combined matrix-isolation IR spectra and ab initio calculations showed that the N9H tautomer dominates in such conditions. Due to an intramolecular interaction between the $\mathrm{N} 9 \mathrm{H}$ group and the lone electron pair of the N3 atom, the N9H tautomer is favored for neutral purine in the gas phase and in non-polar solvents [23-33]. Most studies on the structure of purine in the gas phase are theoretical. There are only a few experimental reports, probably because of high melting point of purine $\left(215^{\circ} \mathrm{C}\right)$. The first direct experimental evidence that in the gas phase the $\mathrm{N} 9 \mathrm{H}$ tautomer is the favored form, has been reported by Caminati et al. [29] who used a free jet milimeter wave absorption spectrometer. The observed rotational spectrum clearly showed that the assigned rotational lines belong to the N9H tautomer. In the gas phase UV PES study, performed earlier for purine by LeBreton and coworkers [28], the assignment of the observed signals to the $\mathrm{N} 9 \mathrm{H}$ form can be considered as indirect. In this case, the interpretation has been based on comparison of the UV photoelectron spectra for purine and for its 7- and 9-methyl derivatives. The $\mathrm{CH}$ tautomers have been usually neglected in the tautomeric mixture of neutral purine [8-31]. However, it has been found recently that they become very important for anionic forms of nucleobases, adenine and guanine [34-36], and for uric acid [37, 38]. They are also favored for reduced aromatic imidazole and aniline as well as for reduced aliphatic vinylamine-acetaldimine [39, 40]. For these reasons, the complete tautomeric mixture (including $\mathrm{CH}$ tautomers) has been considered for investigations of tautomeric equilibria for purine in the gas phase $[32,33]$. 
Many factors such as polarity, aromaticity, intra- and/or intermolecular interactions, stability of functionalities, substituent and solvent effects, UV, $\gamma$-, and X-ray, oxidizing and reducing agents, etc. influence tautomeric equilibria, and consequently, chemical and biochemical properties of tautomeric systems. In this work, we concentrate our attention on solvent effect. We study the effect of water on prototropic equilibria and on $\pi$-electron delocalization for neutral purine $\mathbf{P}$ and for its two charged radicals, the radical cation $\mathbf{P}^{+\cdot}$ and the radical anion $\mathbf{P}^{-\cdot}$. The charged radicals can be formed in the presence of oxidizing or reducing agents. They may also be generated electrochemically, photochemically, or in mass spectrometers during positive $\left(\mathbf{P} \rightarrow \mathbf{P}^{+\bullet}\right)$ or negative ionization $\left(\mathbf{P} \rightarrow \mathbf{P}^{-\bullet}\right)$. Transfer of an electron from or to tautomeric purine may change the stabilities of individual tautomers, and consequently it may change the composition of the tautomeric mixture. These changes may affect the mechanism of proton-transfer and ion-radical reactions.

For investigations, we chose quantum-chemical methods, the density functional theory (DFT) [41] with the Becke threeparameter hybrid exchange functional and the non-local correlation functional of Lee, Yang, and Parr (B3LYP) [42, 43], and the polarizable continuum model (PCM) [44, 45]. For calculations, the $6-311+G(d, p)$ basis set [46] with the diffuse and polarization functions was employed similarly as previously described for the gas phase purine structures [32, 33]. The B3LYP functional and the basis set with the diffuse and polarization functions have been recommended in the literature for charged radicals [47-49]. Both methods have already been applied for charged radicals of nucleobases, and for estimations of their ionization potentials and electron affinities [48-51]. Our computations give the possibilities to study the variations of geometric and energetic parameters, spin densities, charges, geometry-based indices of aromaticity, ionization potentials and electron affinities for all individual purine tautomers when proceeding from the gas phase to water. Since the geometry-based harmonic oscillator model of aromaticity (HOMA) index reformulated by Krygowski in 1993 [52] is not appropriate for heteroatomic compounds $[6,33,39,40]$, the new parametrized harmonic oscillator model of electron delocalization (HOMED) index $[53,54]$ was applied to determine the distribution of $\pi$ electrons for all neutral and charged $\mathrm{NH}$ and $\mathrm{CH}$ purine tautomers. The discrepancies of the reformulated HOMA index are also discussed.

\section{Computational details}

Geometries of neutral, oxidized, and reduced tautomers of purine in their ground states were fully optimized without symmetry constraints at the DFT(B3LYP)/6-311+G(d,p) level $[41-43,46]$. The restricted B3LYP functional was used for the neutral molecules, and the unrestricted B3LYP functional was applied for the charged species. For all isomers, frequencies were calculated to prove that the structures are minima. Next, the B3LYP/6-311+G(d,p) structures were re-optimized at the $\mathrm{PCM}($ water $) / / \mathrm{B} 3 \mathrm{LYP} / 6-311+\mathrm{G}(\mathrm{d}, \mathrm{p})$ level of theory [41-46]. All calculations were performed using the Gaussian 03 package [55]. The adiabatic ionization potentials (IP) and the adiabatic electron affinities (EA) were calculated from Eqs. (1) and (2), respectively, where $E$ s are the total electronic energies of the optimized charged $\left(\mathbf{P}^{+\cdot}\right.$ or $\mathbf{P}^{-\cdot}$ ) and neutral $(\mathbf{P})$ tautomers of purine.

$\mathrm{IP}=E\left(\mathbf{P}^{+\bullet}\right)-E(\mathbf{P})$

$\mathrm{EA}=E(\mathbf{P})-E\left(\mathbf{P}^{-\bullet}\right)$

The geometry-based HOMED indices [53, 54] were estimated for all neutral and charged isomers, optimized at the B3LYP/6-311+G(d,p) and PCM//B3LYP/6-311+G(d,p) levels, using Eq. (3) [52], where $\alpha$ is a normalization constant, $R_{\mathrm{O}}$ is the optimum bond length (assumed to be realized for fully delocalized system), $R_{\mathrm{i}}$ are the running bond lengths in the system, and $n$ is the number of bonds taken into account. The normalization $\alpha$ constants were calculated according to Eq. (4) for the systems containing the even number of bonds (pyrimidine - six bonds, and purine - ten bonds), and according to Eq. (5) for the systems containing the odd number of bonds (imidazole - five bonds). In Eqs. (4) and (5), $R_{\mathrm{S}}$ and $R_{\mathrm{d}}$ are the reference single and double bond lengths, respectively.

HOMED $=1-\left[\alpha \cdot \sum\left(R_{\mathrm{o}}-R_{\mathrm{i}}\right)^{2}\right]: n$

$\alpha=2 \cdot\left\{\left(R_{\mathrm{o}}-R_{\mathrm{s}}\right)^{2}+\left(R_{\mathrm{o}}-R_{\mathrm{d}}\right)^{2}\right\}^{-1}$

$\alpha=(2 \mathrm{i}+1) \cdot\left\{(\mathrm{i}+1) \cdot\left(R_{\mathrm{o}}-R_{\mathrm{S}}\right)^{2}+\mathrm{i} \cdot\left(R_{\mathrm{o}}-R_{\mathrm{d}}\right)^{2}\right\}^{-1}$

For the DFT structures of purine isomers, the following $R_{\mathrm{S}}$, $R_{\mathrm{d}}$, and $R_{\mathrm{O}}$ values (in $\AA$ ), calculated at the $\mathrm{B} 3 \mathrm{LYP} / 6-311+$ $\mathrm{G}(\mathrm{d}, \mathrm{p})$ level [54], were taken here: 1.530 (ethane), 1.329 (ethene), and 1.394 (benzene) for the CC bonds, and 1.466 (methylamine), 1.267 (methylimine), and 1.334 (1,3,5-triazine) for the $\mathrm{CN}$ bonds. The computed $R_{\mathrm{O}}$ bond lengths for the reference aromatic systems (benzene and 1,3,5-triazine) are in accord with the harmonic oscillator method of optimization [52]: $R_{\mathrm{O}}=\left(\mathrm{R}_{s}=\omega \mathrm{R}_{\mathrm{d}}\right) /(1+\omega)$, where $\omega$ (close to 2 for the $\mathrm{CC}$ and $\mathrm{CN}$ bonds) is the ratio of stretching force constants for pure double and pure single bonds. The normalization $\alpha$ constants equal to $78.34(\mathrm{CC})$ and $81.98(\mathrm{CN})$ were applied for the imidazole ring (five bonds), and equal to 88.09 (CC) 
and $91.60(\mathrm{CN})$ for the pyrimidine and purine system (six and ten bonds, respectively). These values are a consequence of normalization of the HOMED index, i.e., HOMED $=1$ for well delocalized aromatic systems - benzene and 1,3,5-triazine, and $\mathrm{HOMED}=0$ for the corresponding odd and even membered systems with localized single and double bonds equal to those for the reference molecules. The use of the same level of theory for the reference molecules and for the $\pi$ electron heteroatomic system has this advantage that the computational errors may cancel out in the procedure of the HOMED estimation [54].

The reference bond lengths calculated in water at the PCM (water)//B3LYP/6-311+G(d,p) level slightly differ from those calculated in the gas phase at the B3LYP/6-311+G(d,p) level. They are as follows (in $\AA$ ): 1.531 (ethane), 1.330 (ethene), 1.396 (benzene), 1.469 (methylamine), 1.270 (methylimine), and 1.335 (1,3,5-triazine). The normalization $\alpha$ constants are also slightly different and equal to 79.59 (CC) and $80.34(\mathrm{CN})$ for the imidazole ring, and equal to 89.32 (CC) and 90.18 (CN) for the pyrimidine and purine system. They were used here for the HOMED estimation for the PCM structures of the purine neutral and redox forms.

\section{Results and discussion}

\section{Choice of methods}

The structural and energetic criteria used to choose the possible factors that can influence the tautomeric equilibria result from the definition of prototropy $[3,6,56]$. According to this definition, prototropic tautomerism is a particular case of isomerism of functional groups. This structural phenomenon occurs for compounds containing at least one proton which can move between at least two conjugated sites. Hence, the structure of tautomeric compounds can be described by a mixture of at least two independent isomers (tautomers) being in equilibrium. Tautomers differ by positions of bond(s) and proton(s). They can be represented by hybrids of various resonance structures [56]. The number of tautomers is a consequence of the number of the labile protons and of the number of the conjugated tautomeric sites. The number of the resonance structures for each tautomer results from the position of the labile proton(s), the number of the labile electrons, and the number of the conjugated sites. For example, Sun and Nicklaus [57] considered ten resonance structures for the $\mathrm{N} 9 \mathrm{H}$ tautomer of purine.

The energetic stability of tautomeric groups, the energetic stability of tautomers, the tautomeric equilibria, and consequently the composition of the tautomeric mixture, by definition, are associated with geometry, and particularly with $\pi$ electron delocalization $[3,6,56]$. A relation between prototropy and electron delocalization has been signaled more than 50 years ago [56] and discussed recently for simple tautomeric systems and for more complex biomolecules [6]. In the literature, tautomeric conversions are frequently described by thermodynamic parameters, e.g., relative energies $(\Delta E)$ between individual tautomers, whereas electron delocalization for $\pi$-electron cyclic systems is described by various aromatic descriptors such as structural, energetic, and magnetic ones [5, 58-60]. For simple fivemembered rings, the geometry-based indices correlate well with the energetic and magnetic ones [60]. However, to obtain the complete information on $\pi$-electron delocalization not all of the aromatic descriptors can be applied to polycyclic tautomeric systems. For example, the magnetic descriptors are local, rather than global, aromatic criteria [60]. They characterize the aromatic (or antiaromatic) character of individual rings in polycyclic compounds. They cannot be applied for the entire polycyclic tautomeric molecule. On the other hand, the energetic descriptors are rather global indices of aromaticity [59]. They describe the aromatic character of the whole cyclic molecule. They cannot be applied for molecular fragments. Exceptionally, the geometry-based indices can measure $\pi$-electron delocalization for mono- and polycyclic systems as well as for the entire molecule and for its fragments [58]. They can be applied for any type of tautomeric system, even for acyclic compounds. For this reason, the geometry-based descriptors was chosen here for the purine tautomers. In the future, the energetic descriptors of electron-delocalization will be analyzed and compared to the geometry-based ones. This comparison for bicyclic purine will give the possibilities to verify the good correlation between the geometry-based and energetic descriptors of aromaticity observed already for simple five-membered rings [60], and will give the possibilities to confirm that the geometry-based indices are a good model for electron delocalization for bicyclic compounds.

The bicyclic tautomeric purine (Fig. 1), consists of pyrimidine and imidazole fused together. Its four $\mathrm{NH}$ tautomers contain ten labile electrons in the purine system. They are delocalized by cross $\pi-\pi$ and $n-\pi$ conjugation. They satisfy the $4 n+2$ rule, and they are aromatic. Five $\mathrm{CH}$ tautomers contain solely eight labile electrons in the purine system. They are also delocalized by cross $\pi-\pi$ conjugation and $\sigma-\pi$ hyperconjugation. They possess one $\mathrm{C}-\mathrm{sp}^{3}$ atom, and they are non-aromatic. For such tautomeric mixture containing the aromatic and non-aromatic forms, the geometry-based HOMED index was chosen. The reasons are as follows. The HOMED index describes well any type of resonance conjugation, weak $\sigma-\pi$ hyperconjugation, medium $\mathrm{n}-\pi$ and $\pi-\pi$ conjugation, and also aromaticity $[53,54]$. This index can be applied to the pyrimidine and imidazole rings as well as to the whole purine system. From mathematical point of view, the procedure of the HOMED index is the same as that of the original HOMA index, proposed in 1972 by Kruszewski and 
Krygowski [61] to describe quantitatively $\pi$-electron delocalization for aromatic systems. One difference is its parametrization [54]. The HOMA index, reformulated by Krygowski in 1993 [52] seems to be inappropriate for $\pi$-electron compounds containing heteroatoms because different measures of $\pi$-electron delocalization were employed for the reference $\mathrm{CC}, \mathrm{CX}$, and XY bonds [39, 54]. It can be used for the systems containing the same type of bonds, e.g., hydrocarbons [62]. It should be mentioned here that the harmonic oscillator model for heterocyclic electron delocalization (HOMHED) index, proposed in 2012 by Frizzo and Martins [63], is based on the hypotheses and ideas of the HOMED index [52-54, 61]. One difference is an application of the statistical reference CC, $\mathrm{CX}$, and $\mathrm{XY}$ bond lengths in the HOMHED procedure. The use of statistical reference bond lengths leads to some kind of statistical HOMHED values which do not describe well the real electron delocalization in heteroatomic systems. For this reason, the HOMHED index was not applied here for the computed structures of the purine isomers.

To study the geometries of all possible individual tautomers and their energetic stabilities, quantum-chemical methods were chosen, because experimental techniques cannot give the complete information on all possible tautomers and on all possible tautomeric equilibria [7-29]. Experimental methods are able to detect solely the major tautomers. The minor and rare isomers cannot be identified when their amounts are too small and their signals cannot be distinguished from the background. This is the main reason for which there are not enough experimental results for comparing theory with experiment. Among various quantum-chemical methods, we chose the DFT method [41] with the B3LYP functional [42, 43], and the 6-311+G(d,p) basis set [46]. The DFT method has already been tested for the parent aliphatic enamine-imine system (vinylamine-acetaldimine) [64, 65], for simple aromatic system imidazole [39] and aniline [40], and also for more complex purine [18]. For vinylamine-acetaldimine, the DFTcalculated relative energies $\left(2-3 \mathrm{kcal} \mathrm{mol}^{-1}\right)$ are close to the high level MP2, G2, CCSD, CCSD(T), and CCSDT ones (3$4 \mathrm{kcal} \mathrm{mol}^{-1}$ ) [64, 65]. For imidazole (building block of purine), the DFT-calculated relative Gibbs energies for the enamine-imine conversions (ca. $17 \mathrm{kcal} \mathrm{mol}^{-1}$ ) are close to the $\mathrm{G} 2$ and G3B3 ones (15-16 kcal mol${ }^{-1}$ ) [39]. For aniline, the DFT-calculated relative Gibbs energies (26-27 kcal mol ${ }^{-1}$ ) for the enamine-imine conversions are close to the $\mathrm{G} 2$ ones $\left(24 \mathrm{kcal} \mathrm{mol}^{-1}\right)$ [40]. The use of different basis set with various polarization and diffuse functions $\{6-311+\mathrm{G}(\mathrm{d}, \mathrm{p}), 6-311++$ $\mathrm{G}(3 \mathrm{df}, 3 \mathrm{pd})$, and aug-cc-pVDZ\} has no important effect on the B3LYP values of the relative thermodynamic parameters for aniline. For bicyclic purine, the MP2 and DFT(B3LYP) methods yield geometries of the same quality [18]. Schaefer III and co-workers [47] considered various quantum-chemical methods for radical ions and for their physicochemical parameters (e.g., EA), and recommended the B3LYP functional for charged species. For all these reasons, the B3LYP/6-311+G(d,p) level of theory was chosen as sufficient for investigations of the structure-energy relation for the tautomeric purine system. To study the solvent effects, the PCM method $[44,45]$ was employed to the neutral and charged forms of purine optimized at the B3LYP/6-311+G(d,p) level. The PCM method has already been tested for tautomeric systems and for charged radicals including nucleobases with the purine system $[39,50$, 66-69]. For future energetic investigations, higher levels of theory will be tested.

\section{Geometries}

All possible nine prototropic tautomers (Fig. 1) were considered for neutral and charged purine in our DFT and PCM computations. The charged radicals were theoretically derived by removing from and adding to the neutral isomer one electron. These transformations refer to one-electron oxidation $\left(\mathbf{P}-\mathrm{e} \rightarrow \mathbf{P}^{+*}\right)$, called also positive ionization, and to oneelectron reduction $\left(\mathbf{P}+\mathrm{e} \rightarrow \mathbf{P}^{-\bullet}\right)$, called also negative ionization. For all neutral and charged tautomers, the minima with real frequencies were found. Generally, the neutral and oxidized tautomers are planar, i.e., all $\mathrm{C}$ and $\mathrm{N}$ atoms are in the plane, except $\mathbf{P 4}, \mathbf{P 5}, \mathbf{P 4}^{+\bullet}$, and $\mathbf{P} 5^{+\bullet}$, where the $\mathrm{C} 4$ and $\mathrm{C} 5$ atoms have the $\mathrm{sp}^{3}$ hybridization. For the same reason, the reduced tautomers $\mathbf{P} 4^{-}$and $\mathbf{P} 5^{-}$are also non-planar. Moreover, the excess electron destroys the planarity of $\mathbf{P} 1^{-\cdot}, \mathbf{P} 3^{-}, \mathbf{P} 7^{-\bullet}$, and $\mathbf{P} 9^{-\cdot}$. The part of tautomer near $\mathrm{N} 1$, $\mathrm{N} 3, \mathrm{~N} 7$, and N9, respectively, has the pyramidal conformation (dihedral $\mathrm{HCNH}$ angle is not larger than $40^{\circ}$ ).

The $\mathrm{CC}$ and $\mathrm{CN}$ bond lengths calculated in the gas phase and in water at the B3LYP/6-311+G(d,p) and PCM(water)// $\mathrm{B} 3 \mathrm{LYP} / 6-311+\mathrm{G}(\mathrm{d}, \mathrm{p})$ levels, respectively, are listed in Table S1 (Supplementary material). Their comparison shows differences in the calculated bond lengths not larger than $0.03 \AA$. Generally, the $\mathrm{CC}$ bond lengths in water vary from 1.37 to $1.50 \AA$ for the neutral isomers, from 1.39 to $1.55 \AA$ for the oxidized isomers, and from 1.39 to $1.51 \AA$ for the reduced isomers, very similarly as those in the gas phase: $1.36-1.51,1.38-1.57$, and $1.39-1.52 \AA$, respectively [32]. Variations of the $\mathrm{CN}$ bond lengths in water: $1.28-1.46,1.25$ 1.46 , and $1.30-1.47 \AA$, respectively, are also almost the same as those in the gas phase: $1.28-1.46,1.25-1.46$, and 1.29 $1.47 \AA$, respectively. The water molecules in the PCM model have only slight effect on the cyclic structures of purine isomers. There are no experimental data for geometries of individual tautomers of neutral and charged purine in the gas phase and in water, and no comparison can be made. In the literature, experimental geometrical parameters have been solely discussed for the crystal $\mathbf{P 7}$ structure $[7,8,24]$. The $\mathrm{CC}$ and $\mathrm{CN}$ bond lengths reported for the crystal $\mathbf{P} 7$ structure are slightly different from those calculated in the gas phase 
and in water, particularly for the $\mathrm{N} 7 \mathrm{C} 8$ and $\mathrm{C} 8 \mathrm{~N} 9$ bonds. These differences result from the fact that the $\mathrm{N} 7 \mathrm{H}$ group and the $\mathrm{N} 9$ atom are engaged in the intermolecular interaction in the crystal $\mathbf{P 7}$ structure.

The $\mathrm{CC}$ and $\mathrm{CN}$ bond lengths strongly depend on the position of the labile proton in the purine tautomers. Their variations are larger for the $\mathrm{CH}$ tautomers than for the $\mathrm{NH}$ ones. However, independently on environment and on oxidation state, all CC bonds are larger than that calculated at the same levels of theory for ethene (1.33 $\AA$ in the gas phase and in water) indicating some $\pi$-electron delocalization for all isomers. In the case of the $\mathrm{NH}$ tautomers, the $\mathrm{CC}$ and $\mathrm{CN}$ bond lengths are very close to those for the fully delocalized aromatic systems, benzene (1.39 and $1.40 \AA$ in the gas phase and in water, respectively) and 1,3,5-triazine (1.33 and $1.34 \AA$, respectively) confirming their aromatic character.

Spin densities and charges

An additional qualitative information on delocalization of $\pi$ electrons can be derived from analyses of the distribution of the unpaired spin density and charge for the redox forms of purine (radical cations and radical anions) in the gas phase (DFT (B3LYP) $/ 6-311+\mathrm{G}(\mathrm{d}, \mathrm{p})\}$ and in water $\{\mathrm{PCM}($ water $) / / \mathrm{DFT}$ (B3LYP) $/ 6-311+\mathrm{G}(\mathrm{d}, \mathrm{p})\}$. In the case of the oxidation reaction, one electron can be removed from $\mathrm{n}$ - or $\pi$-orbital. Since the tautomeric purine system is conjugated $(\pi-\pi, n-\pi$, and $\sigma-\pi)$, the unpaired electron and the positive charge can be delocalized. Indeed, the spin density exists on all atoms of the purine system for the NH and CH tautomers (Table S2, Supplementary material). Most of the spin density is carried by the nitrogen atoms: $\mathrm{N} 1$ and $\mathrm{N} 3$ for $\mathbf{P} 2^{+\bullet}, \mathbf{P} 4^{+\bullet}, \mathbf{P} 6^{+\bullet}-\mathbf{P} 9^{+\bullet}$, and N7 for the other isomers. An important amount is also delocalized on the carbon atoms: $\mathrm{C} 2$ (for $\mathbf{P} 1^{+\bullet}$ and $\mathbf{P} 3^{+\boldsymbol{}}$ ), $\mathrm{C} 4$ (for $\mathbf{P} 1^{+\bullet}$ and $\mathbf{P} 3^{+\boldsymbol{}^{*}}$ ), $\mathrm{C} 5$ (for $\mathbf{P} 2^{+\bullet}, \mathbf{P} 4^{+\bullet}, \mathbf{P} 6^{+\bullet}-\mathbf{P} 9^{+\bullet}$ ), $\mathrm{C} 6$ (for $\mathbf{P} 1^{+\bullet}$ and $\mathbf{P} 3^{+\bullet}$ ), C8 (for $\mathbf{P} 3^{+\bullet}$ ), and also on the $\mathrm{N} 9$ atom (for $\mathbf{P} 1^{+\bullet}$ and $\mathbf{P} 5^{+\bullet}$ ). Since geometries of the purine radical cations do not vary very much when proceeding from the gas phase (DFT) to aqueous solution (PCM), similar trend is observed in water for the distribution of the unpaired spin density. The spin density exists on all atoms of the purine system and its concentration for each atom is very similar to that for the DFT structures.

In the case of the radical anions, the unpaired electron and the negative charge are also delocalized. Most of the spin density is carried by the carbon atoms: C6 (for $\mathbf{P} 1^{-\bullet}, \mathbf{P} 3^{-\bullet}, \mathbf{P} 4^{-\bullet}, \mathbf{P} 5^{-\bullet}, \mathbf{P} 7^{-\bullet}, \mathbf{P} 8^{-\bullet}$, and $\mathbf{P} 9^{-{ }^{-}}$), $\mathbf{C} 2$ (for $\mathbf{P} 3^{-{ }^{-}}$and $\mathbf{P} 5^{-\bullet}$ ), C4 (for $\mathbf{P} 1^{-\bullet}, \mathbf{P} 3^{-\bullet}, \mathbf{P} 5^{-}$, and $\mathbf{P} 7^{-}{ }^{\bullet}$ ), $\mathrm{C} 5$ (for $\mathbf{P} 2^{-\bullet}$ and $\mathbf{P} 6^{-}$), and $\mathrm{C} 8$ (for $\mathbf{P}^{-{ }^{-}}, \mathbf{P 3}^{-}, \mathbf{P 6}^{-}, \mathbf{P} 7^{-}{ }^{-}$, and $\mathbf{P} 9^{-}{ }^{-}$). For some isomers, high concentration of spin density exists also on the nitrogen atoms: $\mathrm{N} 1$ (for $\mathbf{P} 2^{-{ }^{-}}, \mathbf{P} 4^{-{ }^{-}}, \mathbf{P} 6^{-}{ }^{*}$, and $\mathbf{P} 7^{-{ }^{-}}$), N3 (for $\mathbf{P} 2^{-}{ }^{-}, \mathbf{P} 3^{-\bullet}, \mathbf{P} 4^{-\bullet}, \mathbf{P} 6^{-}, \mathbf{P} 7^{-\bullet}$, and $\mathbf{P} 9^{-\bullet}$ ), N7 (for $\mathbf{P} 4^{-}, \mathbf{P} 5^{-}$, and $\mathbf{P} 8^{-\bullet}$ ), and $\mathrm{N} 9$ (for $\mathbf{P} 4^{-\bullet^{-}}$and $\mathbf{P} 8^{-\bullet}$ ). Similar trend is observed in water (PCM) for the distribution of the unpaired spin density. The PCM concentrations of the spin density are very similar to those for the DFT structures.

The differences between the Mulliken charges of the redox and neutral tautomers for the $\mathrm{C}$ and $\mathrm{N}$ atoms (Table S3, Supplementary material) follow the trend observed for the distribution of the unpaired spin density. Generally, the distribution of the charge strongly depends on the position of the labile proton. The $\mathrm{N}$ or $\mathrm{C}$ atom, which takes the labile proton, participates very little in delocalization of the charge. For other atoms of the radical cations, larger concentrations of the positive charge occur for the nitrogen atoms than for the carbon atoms. In the case of the radical anions, the carbon atoms possess larger concentrations of the negative charge for the $\mathrm{NH}$ tautomers, and the nitrogen atoms for the $\mathrm{CH}$ tautomers. The charges computed additionally by natural population analysis (NPA) lead to similar changes when proceeding from the neutral to charged radicals (Table S4, Supplementary material) as those observed on the basis of the Mulliken charges. The positive charge for the radical cations and the negative charge for the radical anions are well delocalized for all isomers.

\section{Geometry-based indices of $\pi$-electron delocalization}

The distribution of unpaired spin density for the charged radicals and the variations of the charges on heavy atoms when proceeding from the neutral to charged tautomers of purine give solely the qualitative information on electron delocalization. To quantitatively measure delocalization of nand $\pi$-electrons, the geometry-based index can be applied to the $\mathrm{NH}$ and $\mathrm{CH}$ structures of neutral and redox forms of purine optimized at the B3LYP/6-311+G(d,p) and PCM//B3LYP/6$311+\mathrm{G}(\mathrm{d}, \mathrm{p})$ levels. In the literature, the HOMA index, reformulated by Krygowski in 1993 [52] and called here the rHOMA index, has been very often applied to describe $\pi$ electron delocalization for mono- and polycyclic, homo- and heteroaromatic systems $[58,59]$, even recently for the four neutral NH tautomers of purine [31].

The rHOMA procedure is based on the original HOMA Eq. (3) $[52,58,61]$. For the original HOMA index, the normalization $\alpha$ constant equal to 98.89 was used for all CC, CX, and XY bonds [70]. In 1993 [52], Krygowski proposed to calculate the normalization $\alpha$ constants from Eq. (4), which corresponds to the systems containing the even number of bonds. Krygowski proposed also the new reference molecules for calculation of the normalization $\alpha$ constants. In the case of aromatic systems containing the $\mathrm{C}$ and $\mathrm{N}$ atoms, moderately delocalized 1,3-butadiene was employed as the reference molecule for the single and double $\mathrm{CC}$ bonds, whereas very weakly delocalized methylamine and methylimine were used as the reference molecules for the single and double $\mathrm{CN}$ bonds, respectively [52]. The use 
of different measures of $\pi$-electron delocalization for the reference molecules has led to the completely different normalization $\alpha$ constants for the $\mathrm{CC}(257.7)$ and $\mathrm{CN}$ bonds (93.52), and consequently, to the artificial rHOMA indices, negative or close to zero for weakly and even moderately delocalized $\pi$-electron heteroatomic systems $[6,53,54]$. Similar results are found for the purine $\mathrm{CH}$ tautomers (Table 1), for which the rHOMA values were calculated for the five- and six-memberred rings (five and six bonds), and also for the whole tautomeric purine system (ten bonds). Although the purine $\mathrm{CH}$ tautomers are $\pi-\pi$ and $\sigma-\pi$ conjugated, their rHOMA indices are negative or close to zero. However, when cyclic compounds of similar electron delocalization (cyclohexane, cyclohexene, benzene, piperidine, 2,3,4,5-tetrahydropyrimidine and 1,3,5-triazine) were applied as the reference molecules for the $\mathrm{CC}$ and $\mathrm{CN}$ bonds, the HOMA indices for the neutral $\mathrm{NH}$ and $\mathrm{CH}$ isomers of purine are between 0.3 and 1.0 [33].

Taking the discrepancies of the rHOMA values into account, the HOMED index was applied to describe properly $\pi$ electron delocalization for all isomers of neutral and redox purine in the gas phase and in water. The new abbreviation HOMED for the geometry-based index and its new parametrization were proposed in 2006 [53]. The HOMED index was defined in this way that it could measure any type of resonance effect possible for $\pi$-electron delocalized systems such as $\sigma-\pi$ hyperconjugation, $n-\pi$ conjugation, $\pi-\pi$ conjugation, and aromaticity. The HOMED index is a modification of the original HOMA index, proposed for heteroaromatic compounds [70]. Equation (3) for the HOMED estimation is the same as that for the original and reformulated HOMA index. In the HOMED procedure, the simple molecules of similar $\pi$-electron delocalization were applied for the reference $\mathrm{CC}$ and $\mathrm{CX}$ bonds $[53$, 54]. For $\mathrm{C}$ and $\mathrm{N}$ containing compounds, they are the same as those for the original HOMA index but different from those for the reformulated HOMA index. The principal difference between the original HOMA and HOMED indices is a use of different normalization $\alpha$ constants for the $\mathrm{CC}$ and $\mathrm{CX}$ bonds. In the case of purine tautomers, the normalization $\alpha$ constants for the HOMED index were calculated from Eq. (4) for the pyrimidine ring (six bonds) and for the purine system (ten bonds) containing the even number of bonds, and from Eq. (5) for the imidazole ring (five bonds) containing the odd number of bonds [54]. The other difference between the original HOMA and HOMED indices is a use of the computed reference bond lengths for the computed structures [54].

The HOMED indices estimated on the basis of the theoretically derived bond lengths for the neutral and redox forms of purine in the gas phase $\{\mathrm{B} 3 \mathrm{LYP} / 6-311+\mathrm{G}(\mathrm{d}, \mathrm{p})\}$ and in water $\{\mathrm{PCM}($ water $) / / \mathrm{B} 3 \mathrm{LYP} / 6-311+\mathrm{G}(\mathrm{d}, \mathrm{p})\}$ are compared in Table 2. For the neutral NH tautomers, the HOMED values are close to unity $(>0.85)$ for the imidazole and purine

Table 1 The rHOMA indices for imidazole ( 5 bonds), pyrimidine ( 6 bonds) and purine system (10 bonds) of neutral and redox tautomers of purine calculated in water at the PCM(water)//B3LYP/6-311+G(d,p) level and in the gas phase at the B3LYP/6-311+G(d,p) level (data in italic)

\begin{tabular}{|c|c|c|c|c|c|c|c|c|c|}
\hline \multirow[b]{2}{*}{ Isomer } & \multicolumn{3}{|c|}{ Neutral form } & \multicolumn{3}{|c|}{ Radical cation } & \multicolumn{3}{|c|}{ Radical anion } \\
\hline & 5 & 6 & 10 & 5 & 6 & 10 & 5 & 6 & 10 \\
\hline \multirow[t]{2}{*}{ P1 } & 0.788 & 0.812 & 0.865 & 0.598 & 0.829 & 0.774 & 0.912 & 0.758 & 0.825 \\
\hline & 0.668 & 0.666 & 0.778 & 0.612 & 0.839 & 0.784 & 0.897 & 0.650 & 0.770 \\
\hline \multirow[t]{2}{*}{$\mathbf{P 2}$} & 0.314 & 0.073 & 0.300 & -0.322 & -0.631 & -0.156 & 0.809 & 0.296 & 0.544 \\
\hline & 0.243 & 0.016 & 0.254 & -0.594 & -0.846 & -0.302 & 0.775 & 0.278 & 0.535 \\
\hline \multirow[t]{2}{*}{ P3 } & 0.835 & 0.888 & 0.900 & 0.641 & 0.824 & 0.796 & 0.929 & 0.783 & 0.839 \\
\hline & 0.762 & 0.817 & 0.849 & 0.646 & 0.834 & 0.796 & 0.928 & 0.745 & 0.818 \\
\hline \multirow[t]{2}{*}{ P4 } & -0.035 & 0.035 & 0.146 & -0.973 & -0.813 & -0.381 & -0.083 & 0.185 & 0.304 \\
\hline & -0.134 & -0.032 & 0.093 & -1.276 & -1.056 & -0.546 & -0.152 & 0.138 & 0.272 \\
\hline \multirow[t]{2}{*}{ P5 } & 0.023 & -0.146 & 0.081 & 0.169 & -0.138 & 0.180 & -0.176 & -0.188 & 0.089 \\
\hline & -0.106 & -0.366 & -0.061 & -0.002 & -0.525 & -0.063 & -0.258 & -0.559 & -0.129 \\
\hline \multirow[t]{2}{*}{ P6 } & 0.188 & -0.189 & 0.138 & -0.452 & -0.906 & -0.320 & 0.864 & 0.214 & 0.498 \\
\hline & 0.112 & -0.255 & 0.076 & -0.884 & -1.293 & -0.573 & 0.834 & 0.188 & 0.480 \\
\hline \multirow[t]{2}{*}{ P7 } & 0.881 & 0.965 & 0.938 & 0.882 & 0.922 & 0.935 & 0.880 & 0.870 & 0.874 \\
\hline & 0.831 & 0.966 & 0.914 & 0.848 & 0.915 & 0.918 & 0.777 & 0.882 & 0.848 \\
\hline \multirow[t]{2}{*}{ P8 } & 0.089 & 0.420 & 0.353 & -0.323 & -0.015 & 0.053 & 0.028 & 0.698 & 0.489 \\
\hline & 0.040 & 0.367 & 0.318 & -0.458 & -0.121 & -0.018 & -0.019 & 0.643 & 0.462 \\
\hline \multirow[t]{2}{*}{ P9 } & 0.861 & 0.970 & 0.929 & 0.844 & 0.903 & 0.913 & 0.888 & 0.848 & 0.858 \\
\hline & 0.834 & 0.976 & 0.915 & 0.813 & 0.894 & 0.895 & 0.848 & 0.856 & 0.850 \\
\hline
\end{tabular}

The rHOMA indices estimated according to Eq. (3) using the following $\alpha$ and $R_{\mathrm{o}}$ (in $\AA$ ): 257.7 and 1.388 for CC, and 93.52 and 1.334 for $\mathrm{CN}$ [52] 
Table 2 Comparison of the HOMED indices for imidazole ( 5 bonds), pyrimidine ( 6 bonds) and purine system ( 10 bonds) of neutral and redox tautomers of purine estimated in water at the PCM(water)//B3LYP/6-
$311+\mathrm{G}(\mathrm{d}, \mathrm{p})$ level with those found in the gas phase at the B3LYP/6$311+\mathrm{G}(\mathrm{d}, \mathrm{p})$ level (data in italic)

\begin{tabular}{|c|c|c|c|c|c|c|c|c|c|}
\hline \multirow[b]{2}{*}{ Isomer } & \multicolumn{3}{|c|}{ Neutral form } & \multicolumn{3}{|c|}{ Radical cation } & \multicolumn{3}{|c|}{ Radical anion } \\
\hline & 5 & 6 & 10 & 5 & 6 & 10 & 5 & 6 & 10 \\
\hline \multirow[t]{2}{*}{ P1 } & 0.927 & 0.923 & 0.934 & 0.758 & 0.951 & 0.854 & 0.951 & 0.817 & 0.865 \\
\hline & 0.889 & 0.851 & 0.890 & 0.755 & 0.931 & 0.842 & 0.953 & 0.728 & 0.818 \\
\hline \multirow[t]{2}{*}{ P2 } & 0.656 & 0.424 & 0.519 & 0.435 & 0.152 & 0.321 & 0.921 & 0.444 & 0.637 \\
\hline & 0.608 & 0.381 & 0.476 & 0.325 & 0.052 & 0.243 & 0.906 & 0.420 & 0.621 \\
\hline \multirow[t]{2}{*}{ P3 } & 0.927 & 0.953 & 0.943 & 0.797 & 0.943 & 0.872 & 0.951 & 0.855 & 0.885 \\
\hline & 0.898 & 0.915 & 0.912 & 0.783 & 0.917 & 0.848 & 0.949 & 0.808 & 0.857 \\
\hline \multirow[t]{2}{*}{ P4 } & 0.411 & 0.474 & 0.423 & 0.114 & 0.212 & 0.248 & 0.476 & 0.595 & 0.562 \\
\hline & 0.345 & 0.429 & 0.375 & -0.013 & 0.119 & 0.167 & 0.430 & 0.568 & 0.534 \\
\hline \multirow[t]{2}{*}{ P5 } & 0.473 & 0.543 & 0.505 & 0.626 & 0.606 & 0.635 & 0.456 & 0.633 & 0.592 \\
\hline & 0.411 & 0.439 & 0.428 & 0.549 & 0.440 & 0.519 & 0.421 & 0.604 & 0.574 \\
\hline \multirow[t]{2}{*}{ P6 } & 0.616 & 0.369 & 0.480 & 0.397 & 0.152 & 0.323 & 0.936 & 0.568 & 0.713 \\
\hline & 0.554 & 0.323 & 0.427 & 0.235 & 0.000 & 0.206 & 0.920 & 0.554 & 0.700 \\
\hline \multirow[t]{2}{*}{ P7 } & 0.928 & 0.991 & 0.963 & 0.956 & 0.974 & 0.968 & 0.920 & 0.904 & 0.899 \\
\hline & 0.879 & 0.990 & 0.930 & 0.928 & 0.972 & 0.954 & 0.846 & 0.924 & 0.875 \\
\hline \multirow[t]{2}{*}{ P8 } & 0.418 & 0.731 & 0.554 & 0.252 & 0.556 & 0.409 & 0.363 & 0.906 & 0.630 \\
\hline & 0.379 & 0.696 & 0.522 & 0.190 & 0.516 & 0.374 & 0.339 & 0.881 & 0.614 \\
\hline \multirow[t]{2}{*}{ P9 } & 0.907 & 0.993 & 0.947 & 0.934 & 0.969 & 0.955 & 0.919 & 0.911 & 0.902 \\
\hline & 0.873 & 0.994 & 0.928 & 0.903 & 0.965 & 0.938 & 0.885 & 0.923 & 0.892 \\
\hline
\end{tabular}

rings, and also for the whole tautomeric purine system. This confirms quantitatively their aromatic character. In the case of the neutral $\mathrm{CH}$ tautomers, the HOMED values are lower than 0.75 but larger than 0.30 for individual rings. Lower HOMED values are found for the ring possessing the labile proton $\left(\mathrm{C}-\mathrm{sp}^{3}\right.$ atom $)$ than for the other one. For the whole purine system of the neutral $\mathrm{CH}$ tautomers, the HOMED values are between 0.35 and 0.55 . This confirms that the neutral $\mathrm{CH}$ tautomers are non-aromatic. The $\mathrm{C}$-ring atom, taking the labile proton, loses its $\mathrm{sp}^{2}$ hybridization, and the $\mathrm{CH}$ group can only be $\sigma-\pi$ hyperconjugated with $\pi$-electrons of the $\mathrm{C}=\mathrm{N}$ groups. Therefore, the $\mathrm{CH}$ forms are less delocalized than the $\mathrm{NH}$ ones.

The comparison of the HOMED values for the neutral and redox forms of purine in the gas phase (DFT) and in water (PCM) shows evidently that $\pi$-electron delocalization is less sensitive to solvation than to electron transfer from and to purine molecule. Generally, the HOMED values augment (by less than 0.2 units) when proceeding from the gas phase (DFT) structures to the aqueous (PCM) ones, probably due to intermolecular interactions of polar groups with polar solvent molecules (water). One-electron oxidation and oneelectron reduction change the HOMED indices in different ways, in some cases even by more than 0.2 units. For the oxidized NH tautomers, the HOMED values increase for the ring possessing the labile proton, and they decrease for the other one. For the oxidized $\mathrm{CH}$ tautomers, they decrease for both rings (except $\mathbf{P} 5^{+\bullet}$ ). For the reduced $\mathrm{NH}$ tautomers, the HOMED values decrease for the pyrimidine ring and they increase for the imidazole ring (except $\mathbf{P} 7^{-}{ }^{\circ}$ ). For the reduced $\mathrm{CH}$ tautomers, they increase for both rings (except the imidazole ring for $\mathbf{P} 5^{-\bullet}$ and $\mathbf{P} 8^{-\bullet}$ ).

The estimated HOMED values are consistent with a general trend of the resonance conjugation: more delocalized system, larger HOMED index value [54]. They are well normalized. Their values are between 0 and 1 for neutral isomers. Unfortunately, this is not true for the rHOMA indices. Therefore, the rHOMA values against the HOMED values for the neutral, oxidized, and reduced tautomers give scatter plots (Fig. 2). The discrepancies for the rHOMA values are greater for moderately and weak delocalized non-aromatic $\mathrm{CH}$ tautomers than for well delocalized aromatic $\mathrm{NH}$ ones. For the NH tautomers, differences between the running and optimum bond lengths are very low, and thus they slightly influence the rHOMA values. Hence, it is no wonder that the rHOMA values estimated recently for the neutral NH tautomers of purine correlate quite well with the relative energies [31]. The rHOMA and HOMED values estimated for individual rings of the aromatic $\mathrm{NH}$ tautomers are also in line with the magnetic (NICS) index values [31]. For the $\mathrm{CH}$ tautomers, differences between the running and optimum bond lengths are considerably greater, and consequently, the use of 

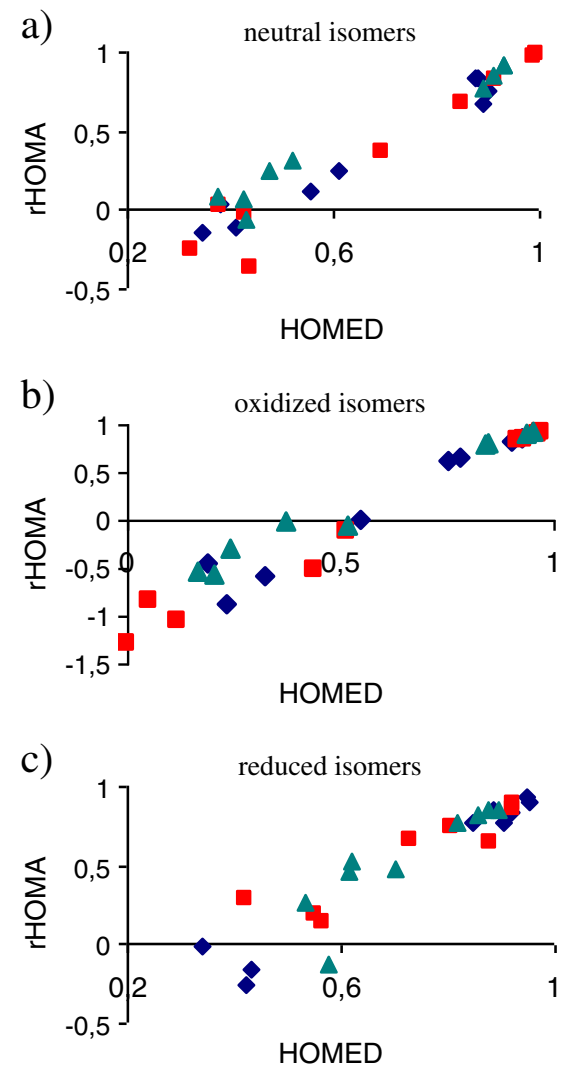

Fig. 2 rHOMA vs HOMED (DFT) for the imidazole (blue points) and pyrimidine (red points) rings, and for the whole purine system (green points) of the neutral (a), oxidized (b), and reduced (c) purine isomers

considerably larger $\alpha$ value for CC (257.7) than $\mathrm{CN}$ (93.52) bonds strongly reduces the rHOMA values that in many cases they are negative. Lack of linear correlation between the rHOMA and HOMED values is a consequence of the use of the different measures for the $\mathrm{CC}$ and $\mathrm{CN}$ bonds in the rHOMA procedure. This is inappropriate for the heteroatomic conjugated systems and leads to the artificial rHOMA values which do not describe well real electron delocalization in the heteroatomic systems.

\section{Relative stabilities}

The total electronic energies (Table S5, Supplementary material) calculated for all purine tautomers optimized in water at the PCM(water)//DFT(B3LYP)/6-311+G(d,p) level can be compared with those found in the gas phase at the DFT(B3LYP) $/ 6-311+G(d, p)$ level. Generally, the aromatic NH tautomers (P1, P3, P7, and P9) have lower energies than the non-aromatic $\mathrm{CH}$ ones $(\mathbf{P 2}, \mathbf{P 4}, \mathbf{P 5}, \mathbf{P 6}$, and $\mathbf{P 8})$. For the neutral purine tautomers, their energies increase in the following orders: $\mathbf{P 9}<\mathbf{P 7}<\mathbf{P 1}<\mathbf{P 3}<\mathbf{P 8}<\mathbf{P 2}<$ P5 $<$ P6 $<$ P4 in water and $\mathbf{P 9}<\mathbf{P} 7<\mathbf{P 3}<\mathbf{P 1}<\mathbf{P 8}<\mathbf{P 2}<\mathbf{P 6}<$ P5 $<$ P4 in the gas phase. The orders are very similar, but the relative energies in water are slightly different than those in the gas phase (Table 3). The N9H tautomer is favored in the tautomeric mixture of neutral purine in the gas phase. In water, two tautomers, $\mathrm{N} 7 \mathrm{H}$ and $\mathrm{N} 9 \mathrm{H}$, have similar energies, and they dominate in the tautomeric mixture. This is in good agreement with the literature experimental and theoretical data for neutral purine [8-33].

Interesting mechanisms for solvent-mediated tautomerization of neutral purine have been proposed by Lee and coworkers on the basis of DFT and MP2 calculations [71]. Authors considered various pathways with one or more steps for tautomeric conversions $(\mathrm{N} 9 \mathrm{H} \rightarrow \mathrm{C} 8 \mathrm{H} \rightarrow \mathrm{N} 7 \mathrm{H}, \mathrm{N} 9 \mathrm{H} \rightarrow \mathrm{N} 3 \mathrm{H}$, and $\mathrm{N} 9 \mathrm{H} \rightarrow \mathrm{N} 3 \mathrm{H} \rightarrow \mathrm{N} 1 \mathrm{H} \rightarrow \ldots \rightarrow \mathrm{N} 7 \mathrm{H}$ ). In the absence of the water molecules, they found large barriers $\left(\geq 60 \mathrm{kcal} \mathrm{mol}^{-1}\right)$ for the intramolecular proton-transfer. These barriers explain the preference of one N9H tautomer in the gas phase $[28,29]$ and in low-temperature rare-gas matrices [22-27]. Microsolvation, particularly hydrogen bonding with water molecules, dramatically lowers the barriers (by $30-40 \mathrm{kcal} \mathrm{mol}^{-1}$ ) of the tautomeric conversions by the concerted multipole proton transfer mechanism. This may explain almost equal amounts of the $\mathrm{N} 9 \mathrm{H}$ and N7H tautomers in aqueous solution, experimentally proved by various spectroscopic techniques [12-17]. Lee and co-workers showed additionally that microsolvation by one water molecule also affects the relative stabilities of individual tautomers but in smaller degree than microsolvation by two or three water molecules and macrosolvation in the PCM model discussed here.

A removal of one electron from neutral purine does not change very much low stability of the $\mathrm{CH}$ tautomers in comparison to the $\mathrm{NH}$ ones. However, it changes the relative stabilities of the major $\mathrm{NH}$ tautomers. The order of the relative energies in water $\mathbf{P} 1^{+\bullet^{\bullet}}<\mathbf{P} 9^{+\bullet^{\bullet}}<\mathbf{P} 7^{+\bullet^{*}}<\mathbf{P} 3^{+\bullet^{*}}<\mathbf{P} 8^{+\bullet^{*}}<\mathbf{P} 2^{+\bullet^{*}}<\mathbf{P} 5^{+\bullet^{*}}<\mathbf{P} 6^{+\bullet^{*}}<\mathbf{P} 4^{+{ }^{+}}$ is completely different from that in the gas phase

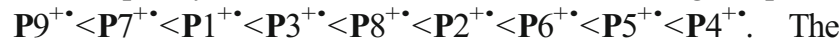
$\mathrm{N} 1 \mathrm{H}$ tautomer seems to be favored in water, whereas the $\mathrm{N} 9 \mathrm{H}$ one predominates in the gas phase. For the other NH tautomers, the relative energies are lower than 5 and $10 \mathrm{kcal} \mathrm{mol}^{-1}$ in water and in the gas phase, respectively. This indicates that in water, all four $\mathrm{NH}$ tautomers $(\mathrm{N} 1 \mathrm{H}, \mathrm{N} 9 \mathrm{H}, \mathrm{N} 7 \mathrm{H}$, and $\mathrm{N} 3 \mathrm{H})$ should be considered in the electron-transfer processes in which purine loses one electron, whereas solely two tautomers $(\mathrm{N} 9 \mathrm{H}$ and $\mathrm{N} 7 \mathrm{H})$ may be taken into account in the gas phase. The relative energies for the $\mathrm{CH}$ tautomers are larger than $45 \mathrm{kcal} \mathrm{mol}^{-1}$. Their contributions in the oxidized tautomeric mixture may be neglected for both phases similarly as for neutral purine.

When purine gains one-electron in reduction processes, stabilities of the purine tautomers dramatically change. The reduced $\mathrm{NH}$ and $\mathrm{CH}$ tautomers have very close energies (except $\mathrm{C} 4 \mathrm{H}$ and $\mathrm{C} 5 \mathrm{H}$ ), and consequently, their orders of stabilities completely differ from those for the neutral and oxidized tautomers. The order of stabilities is also different in water:

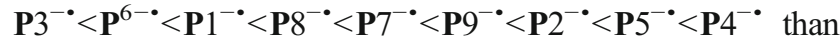
that in the gas phase: $\mathbf{P} 6^{-}<\mathbf{P} 8^{-{ }^{-}}<\mathbf{P} 3^{-{ }^{-}}<\mathbf{P} 2^{-{ }^{-}}<\mathbf{P} 9^{-{ }^{-}}<\mathbf{P} 7^{-}$ $<\mathbf{P} 1^{-\cdot}<\mathbf{P} 5^{-\cdot}<\mathbf{P} 4^{-\bullet}$. The N3H tautomer seems to be favored 
Table 3 The DFT (gas) and PCM (water) relative energies (in $\mathrm{kcal} \mathrm{mol}^{-1}$ at $0 \mathrm{~K}$ ) calculated for the neutral and redox forms of purine

\begin{tabular}{|c|c|c|c|c|c|c|}
\hline \multirow[b]{2}{*}{ Isomer } & \multicolumn{2}{|c|}{ Neutral form } & \multicolumn{2}{|c|}{ Radical cation } & \multicolumn{2}{|c|}{ Radical anion } \\
\hline & DFT & PCM & DFT & PCM & DFT & PCM \\
\hline P1 & 13.1 & 4.4 & 8.2 & 0.0 & 11.3 & 1.4 \\
\hline $\mathbf{P 2}$ & 44.0 & 48.5 & 49.1 & 53.4 & 5.0 & 5.8 \\
\hline P3 & 9.9 & 6.6 & 9.4 & 4.1 & 3.1 & 0.0 \\
\hline P4 & 54.2 & 57.1 & 58.9 & 60.2 & 16.6 & 17.7 \\
\hline P5 & 47.7 & 49.6 & 57.0 & 56.6 & 14.3 & 15.2 \\
\hline P6 & 46.4 & 50.5 & 53.6 & 57.9 & 0.0 & 1.1 \\
\hline P7 & 4.0 & 0.2 & 2.9 & 2.4 & 9.8 & 2.8 \\
\hline P8 & 40.1 & 44.5 & 47.1 & 51.7 & 0.6 & 2.2 \\
\hline P9 & 0.0 & 0.0 & 0.0 & 1.7 & 8.2 & 4.4 \\
\hline
\end{tabular}

in water, whereas the $\mathrm{C} 6 \mathrm{H}$ and $\mathrm{C} 8 \mathrm{H}$ tautomers dominate in the gas phase. The relative energies of the other reduced isomers are lower than $6 \mathrm{kcal} \mathrm{mol}^{-1}$ (except $\mathrm{C} 4 \mathrm{H}$ and $\mathrm{C} 5 \mathrm{H}$ ) at the PCM level. This suggests that seven isomers $(\mathrm{N} 3 \mathrm{H}, \mathrm{C} 6 \mathrm{H}, \mathrm{N} 1 \mathrm{H}$, $\mathrm{C} 8 \mathrm{H}, \mathrm{N} 7 \mathrm{H}, \mathrm{N} 9 \mathrm{H}$, and $\mathrm{C} 2 \mathrm{H}$ ) should be considered for the electron-transfer reactions in which purine gains one electron. In the gas phase, four tautomers $(\mathrm{C} 6 \mathrm{H}, \mathrm{C} 8 \mathrm{H}, \mathrm{N} 3 \mathrm{H}$, and $\mathrm{C} 2 \mathrm{H})$ have the relative energies not larger than $5 \mathrm{kcal} \mathrm{mol}^{-1}$, and thus they may be taken into account for the reduction processes.

The relation between prototropy and electron delocalization seems to be very simple for neutral purine. The decrease of stability of the $\mathrm{CH}$ tautomers in comparison to the $\mathrm{NH}$ ones is parallel to the decrease of $\pi$-electron delocalization. Although intra- and intermolecular interactions in the gas phase and in water (PCM model) influence the stability of the purine isomers, the relative total energies $(\Delta E)$ correlate well with the HOMED(10) indices estimated for the whole tautomeric purine system (Fig. 3). Similar trend occurs for the oxidized purine tautomers. The $\Delta E$ values correlate quite well with the HOMED(10) indices estimated for the whole tautomeric system (Fig. S1, Suplementary material). Some exception is only found for the $\mathrm{C} 5 \mathrm{H}$ tautomer. However, for the reduced purine tautomers at least two subfamilies can be distinguished on the plots of the $\operatorname{HOMED}(10)$ indices against the $\Delta E$ values, one for the $\mathrm{NH}$ tautomers and the other one for the $\mathrm{CH}$ forms (Fig. S2, Suplementary material). There is no simple relation between prototropy and electron delocalization for reduced tautomers.

Energetic parameters (IP and EA) for positive and negative ionization

Typical mass spectrometric techniques may generate the charged radicals, the radical cations and the radical anions. The charged radicals may also be identified by positive or negative ion photoelectron spectroscopy. However, they are too short-lived to be studied experimentally in detail, and thus, solely a few experimental data can be found in the literature for purine [72]. Quantum-chemical methods are more frequently used to determine the energetic parameters characteristic for the electron-transfer processes [47-51], e.g., the ionization potential (IP) for a loss of one-electron and the electron affinity (EA) for a gain of one-electron. In this paper, we estimated the adiabatic IP and EA values for the purine tautomers using Eqs. (1) and (2), respectively, and the total electronic energies calculated for the neutral and charged isomers at their respective equilibrium geometries.

The DFT adiabatic IP values estimated for all individual tautomers of purine in the gas phase (Table 4) suggest that the positive ionization process $\mathbf{P}-\mathrm{e} \rightarrow \mathbf{P}^{+}$is very endothermic (IP close to $9 \mathrm{eV}, 1 \mathrm{eV}=23.06037 \mathrm{kcal} \mathrm{mol}^{-1}$ ). Moreover, the IP values for the aromatic NH tautomers (8.80-9.02 eV) are slightly lower than those for the nonaromatic $\mathrm{CH}$ ones $(9.22-9.42 \mathrm{eV})$. In water, the PCMcalculated energy differences between the charged and neutral forms (corresponding to the aqueous IPs) are also lower
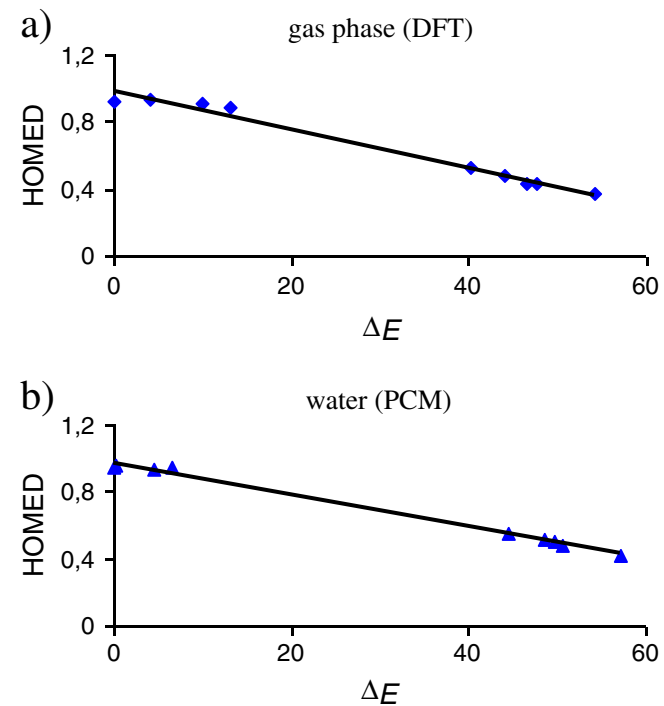

Fig. $3 \mathrm{HOMED(10)}$ vs $\Delta E$ (in $\mathrm{kcal} \mathrm{mol}^{-1}$ ) for the neutral purine isomers in the gas phase (a) and in water (b) 
Table 4 The DFT (gas) and PCM (water) adiabatic ionization potentials and adiabatic electron affinities (IP and EA, respectively, in eV) calculated for individual tautomers of purine in their equilibrium ground electronic states

\begin{tabular}{llllll}
\hline & \multicolumn{2}{l}{ IP } & & \multicolumn{2}{l}{ EA } \\
\cline { 2 - 3 } \cline { 5 - 6 } Tautomer & DFT & PCM & & DFT & PCM \\
\hline P1 & 8.80 & 6.71 & & 0.44 & 2.41 \\
P2 & 9.24 & 7.12 & & 2.06 & 4.13 \\
P3 & 9.00 & 6.80 & & 0.66 & 2.56 \\
P4 & 9.22 & 7.04 & 2.00 & 3.99 \\
P5 & 9.42 & 7.21 & 1.81 & 3.76 \\
P6 & 9.33 & 7.23 & 2.38 & 4.42 \\
P7 & 8.97 & 7.00 & 0.12 & 2.16 \\
P8 & 9.32 & 7.22 & 2.08 & 4.11 \\
P9 & 9.02 & 6.98 & 0.01 & 2.09 \\
\hline
\end{tabular}

for the NH tautomers $(6.71-7.00 \mathrm{eV})$ than for the $\mathrm{CH}$ ones (7.04-7.23 eV). Water molecules diminish the IP values by ca. $2 \mathrm{eV}$. Similar solvent effect for the PCM model has been observed for the ionization potentials of nucleobases [50].

For the favored positive ionization $\mathbf{P} 9-\mathrm{e} \rightarrow \mathbf{P} 9^{+}{ }^{\bullet}$ in the gas phase, the adiabatic ionization potential is equal to $9.02 \mathrm{eV}$. This value, corrected by ZPEs for the neutral and charged forms, leads to IP $(8.97 \mathrm{eV})$, which can be compared to the gas phase experimental IP $(9.35 \pm 0.05 \mathrm{eV})$ determined by photoionization mass spectrometry in the $7-18 \mathrm{eV}$ photon energy region with synchrotron radiation as excitation source [73]. This experimental IP value is considered as being equal or close to the adiabatic value. Other literature IP values for purine (in the range 9.52-9.7 eV [28, 74-76]) correspond to vertical ionization. They were determined by electron impact techniques, photoelectron spectroscopy, and photoionization studies. Similar experimental IP values (8.3-8.9 eV [28, 74, 75, 77-79]) have been found for adenine (6-aminopurine) using the electron impact techniques.

The negative ionization $\mathbf{P}+\mathrm{e} \rightarrow \mathbf{P}^{-\cdot}$ is a more energetically favorable process for the purine tautomers than the positive ionization. All nine purine radical anions are lower in energy than the corresponding neutral isomers. Hence, all of them are stable. This leads to the positive adiabatic EAs (Table 4). In the gas phase, the EA values are lower for the NH tautomers $(0.01-0.66 \mathrm{eV})$ than for the $\mathrm{CH}$ ones $(1.81-2.38 \mathrm{eV})$ indicating that the $\mathrm{CH}$ forms may be more easily transformed to the negatively charged radicals than the $\mathrm{NH}$ ones. This may partially explain the change of the tautomeric preferences when going from neutral $(\mathrm{N} 9 \mathrm{H})$ to reduced purine $(\mathrm{C} 6 \mathrm{H})$. In water, the PCM-calculated energy differences between the neutral and charged forms are also lower for the $\mathrm{NH}$ tautomers $(2.09-2.56 \mathrm{eV})$ than for the $\mathrm{CH}$ ones $(3.76-4.42 \mathrm{eV})$. Water molecules augment the EA values by ca. $2 \mathrm{eV}$. Similar solvent effect has been observed for the electron affinities of nucleobases [51].

For the negative ionization process, we considered two reactions: $\mathbf{P} 9+\mathrm{e} \rightarrow \mathbf{P} 9^{-}$, assuming that addition of oneelectron does not change the tautomeric form of purine during experiment, and $\mathbf{P} 9+\mathrm{e} \rightarrow \mathbf{P} 6^{-}$for the favored tautomeric forms. The DFT calculated EA values are as follows: 0.01 and $0.36 \mathrm{eV}$, respectively. These values, corrected by ZPE for the neutral and charged forms, lead to 0.16 and $0.47 \mathrm{eV}$, respectively. Both values are positive and close to zero. There are no experimental EA for purine in the literature [80] and no other comparison can be made. Even for more important adenine, the situation is not yet clear, probably because of its short-lived anionic states [80-84]. The adiabatic EA value, predicted on the basis of experiments in a time-offlight spectrometer, seems to be close to zero $(0.012 \pm 0.005)$ [81] and the vertical EA value, estimated using low-energy electron transmission spectroscopy, is negative $(-0.54 \mathrm{eV})$ [82]. Numerous papers discussing the nature of the adenine anion (dipole bound anion and/or valence bound one) can be found in the literature. However, recent combined photoelectron experiments and B3LYP calculations indicate that the amine radical anion of adenine favors the $\mathrm{C} 8$ atom for the labile proton and prefers the valence state [34]. Interestingly, the gas phase adiabatic EA value predicted from half-wave reduction potentials in aprotic solvents by using the appropriate reference energy and solution energy difference value, is positive $(0.95 \pm 0.05 \mathrm{eV})[83,84]$.

\section{Conclusions}

Quantum-chemical calculations performed for the neutral and redox forms of purine in the gas phase (DFT) and in water (PCM) show interesting variations of the geometric and energetic parameters, and consequently, of the tautomeric preferences. When going from neutral to oxidized purine in the gas phase, the tautomeric preference does not change $[32,33]$. The N9H tautomer is favored for both oxidation states. Water (PCM model) seems to change this tautomeric preference. For neutral purine, two tautomers $(\mathrm{N} 9 \mathrm{H}$ and $\mathrm{N} 7 \mathrm{H})$ dominate in water. This is in good agreement with the literature data [11-20]. For oxidized purine, the N1H tautomer has lower energy in water than the N9H one by less than $2 \mathrm{kcal} \mathrm{mol}^{-1}$. The $\mathrm{N} 7 \mathrm{H}$ and $\mathrm{N} 3 \mathrm{H}$ tautomers possess energies in water close to that of the $\mathrm{N} 1 \mathrm{H}$ tautomer. Hence, they may be present in the tautomeric mixture. When proceeding from neutral to reduced purine, the tautomeric preferences dramatically change. They are also different in the gas phase and in water indicating that the intramolecular transfer of the proton for reduced purine may be very dependent on environment. In the gas phase, the $\mathrm{C} 6 \mathrm{H}$ tautomer seems to dominate in the tautomeric mixture, whereas the 
$\mathrm{N} 3 \mathrm{H}$ one in water. Other tautomers may also be present in the tautomeric mixture in important amounts, three $(\mathrm{C} 8 \mathrm{H}, \mathrm{N} 3 \mathrm{H}$, and $\mathrm{C} 2 \mathrm{H})$ in the gas phase and six $(\mathrm{C} 6 \mathrm{H}, \mathrm{N} 1 \mathrm{H}, \mathrm{C} 8 \mathrm{H}, \mathrm{N} 7 \mathrm{H}$, $\mathrm{N} 9 \mathrm{H}$, and $\mathrm{C} 2 \mathrm{H}$ ) in water. Aromaticity seems to be the main factor that dictates the tautomeric preferences for neutral and oxidized purine in the gas phase and in water. An addition of one electron to the purine system increases the stability of less delocalized $\mathrm{CH}$ tautomers due to profitable energetic effects, and no simple relation exists between the relative energies and the geometry-based indices of electron delocalization.

Open Access This article is distributed under the terms of the Creative Commons Attribution License which permits any use, distribution, and reproduction in any medium, provided the original author(s) and the source are credited.

\section{References}

1. Pozharskii AF, Soldatenkov AT, Katritzky AR (1997) Heterocycles in life and society. Wiley, New York

2. Saenger W (1994) Principles of nucleic acids structures. Springer, Heidelberg

3. Elguero J, Marzin C, Katritzky AR, Linda P (1976) The tautomerism of heterocycles. Academic, New York

4. Kwiatkowski JS, Person WB (1990) In: Beveridge DL, Lavery R (eds) Theoretical biochemistry and molecular biology. New York, Academic

5. Katritzky AR, Jug K, Oniciu DC (2001) Quantitative measures of aromaticity for mono-, bi-, and tricyclic penta- and hexaatomic heteroaromatic ring systems and their interrelationships. Chem Rev 101:1421-1450

6. Raczyńska ED, Kosińska W, Ośmiałowski B, Gawinecki R (2005) Tautomeric equilibria in relation to pi-electron delocalization. Chem Rev 105:3561-3612, and references therein

7. Watson DG, Sweet RM, Marsh RE (1965) The crystal and molecular structure of purine. Acta Crystallogr 19:573-580

8. Parker SF, Jeans R, Devonshire R (2004) Inelastic neutron scattering, Raman spectroscopy and periodic DFT study of purine. Vibr Spectrosc 35:173-177

9. Majoube M, Henry M, Vergoten G (1994) Vibrational spectra for purine and its ${ }^{15} \mathrm{~N}$ - and D-substituted analogues. Assignment of normal modes from ab initio 3-21G force fields. J Raman Spectrosc 25:233-243

10. Cao X, Fischer G (1999) New infrared spectra and the tautomeric studies of purine and $\alpha \mathrm{L}$-alanine with an innovative sampling technique. Spectrochim Acta 55A:2329-2342

11. Peral F, Gallego E (2000) A study by ultraviolet spectroscopy on self association of purine, 6-methylpurine, benzimidazole, and imidazo[1,2-a]pyridine in aqueous solution. Spectrochim Acta 56A:747-759

12. Chenon MT, Pugmire RJ, Grant DM, Panzica RP, Townsend LB (1975) Carbon-13 magnetic resonance. XXVI. A quantitative determination of the tautomeric populations of certain purines. J Am Chem Soc 97:4636-4642

13. Schumacher M, Guenther H (1982) Carbon-13 proton spin-spin coupling. 9. Purine. J Am Chem Soc 104:4167-4173

14. Gonella NC, Roberts JD (1982) Studies of the tautomerism of purine and the protonation of purine, and its 7- and 9-methyl derivatives, by nitrogen-15 nuclear magnetic resonance spectroscopy. J Am Chem Soc 104:3162-3164
15. Bartl T, Zacharová Z, Sečkářová P, Kolehmainen E, Marek R (2009) NMR quantification of tautomeric populations in biogenic purine bases. Eur J Org Chem 9:1377-1383

16. Majoube M, Millié P, Chinsky L, Turpin PY, Vergoten G (1995) Resonance Raman spectra for purine. J Mol Struct 355:147-158

17. Ten GN, Burova TG, Baranov VI (2004) Investigations of tautomeric purine forms by the methods of vibrational spectroscopy and resonance Raman scattering. I. Modeling of the purine structure in different phase states. Russ Phys J 47:626-637

18. Broo A, Holmn A (1996) Ab initio MP2 and DFT calculations of geometry and solution tautomerism of purine and some purine derivatives. Chem Phys 211:147-161

19. Borin AC, Serrano-Andrs L, Flscher MP, Ross BO (1999) A theoretical study of the electronic spectra of N9 and N7 purine tautomers. J Phys Chem A 103:1838-1845

20. Burova TG, Ten GN, Kucherova VV (2004) Investigations of tautomeric purine forms by the methods of vibrational spectroscopy and resonance Raman scattering. II. Quantum-mechanical calculations of the resonance Raman scattering spectra of purine tautomers. Russ Phys J 47:721-725

21. Stepanian SG, Sheina GG, Radchenko ED, Blagoi YP (1985) Theoretical and experimental studies of adenine, purine and pyrimidine isolated molecule structure. J Mol Struct 131:333-346

22. Nowak MJ, Lapinski L, Kwiatkowski JS (1989) An infrared matrix isolation study of tautomerism in purine and adenine. Chem Phys Lett 157:14-18

23. Kwiatkowski JS, Leszczynski J (1990) Ab initio quantummechanical study of tautomerism of purine, adenine and guanine. J Mol Struct 208:35-44

24. Nowak MJ, Lapinski L, Kwiatkowski JS, Leszczynski J (1991) Infrared matrix isolation and ab initio quantum mechanical studies of purine and adenine. Spectrochim Acta 47A:87-103

25. Nowak MJ, Rostkowska H, Lapinski L, Kwiatkowski JS, Leszczynski J (1994) Experimental matrix isolation and theoretical ab initio HF/6-31G(d, p) studies of infrared spectra of purine, adenine, and 2-chloroadenine. Spectrochim Acta 50A:1081-1094

26. Nowak MJ, Rostkowska H, Lapinski L, Kwiatkowski JS, Leszczynski $\mathrm{J}$ (1994) Tautomerism $\mathrm{N}(9) \mathrm{H} \rightarrow \mathrm{N}(7) \mathrm{H}$ of purine, adenine, and 2chloroadenine: combined experimental IR matrix isolated and ab initio quantum-mechanical studies. J Phys Chem 98:2813-2816

27. Houben L, Schoone K, Smets J, Adamowicz L, Maes G (1997) Combined matrix-isolation FT-IR and ab initio $6-31++\mathrm{G}^{* *}$ studies on tautomeric properties of nucleic acid bases and simpler model molecules. J Mol Struct 410-411:397-401

28. Lin J, Yu, Peng S, Akiyama I, Li K, Lee LK, LeBreton PR (1980) Ultraviolet photoelectron studies of the ground-state electronic structure and gas-phase tautomerism of purine and adenine. J Am Chem Soc 102:4627-4631

29. Caminati W, Maccaferri G, Favero PG, Favero LB (1996) Free jet absorption milimeter wave spectrum of purine. Chem Phys Lett 251:189-192

30. El-Bakali Kassimi N, Thakkar AJ (1996) Polarizabilities of purine, allopurinol, hypoxanthine, xanthine and alloxanthine. J Mol Struct (THEOCHEM) 366:185-193

31. Stasyuk OA, Szatylowicz H, Krygowski TM (2012) Effect of the H-bonding on aromaticity of purine tautomer. J Org Chem 77:4035-4045

32. Raczyńska ED, Kamińska B, Szelag M (2009) Influence of oneelectron oxidation and one-electron reduction on the tautomeric preferences for purine. Anal Bioanal Electrochem 1:83-97

33. Raczyńska ED, Kamińska B (2010) Prototropy and pi-electron delocalization for purine and its radical ions - DFT studies. J Phys Org Chem 23:828-835

34. Chatgilialoglu C, Caminal C, Altieri A, Vougioukalakis GC, Mulazzani QG, Gimisis T, Guerra M (2006) Tautomerism in the guanyl radical. J Am Chem Soc 128:13796-13805 
35. Li X, Bowen KH, Haranczyk M, Bachorz RA, Mazurkiewicz K, Rak J, Gutowski M (2007) Photoelectron spectroscopy of adiabadically bound valence anions of rare tautomers of the nucleic adic bases. J Chem Phys 127:174309/1-6

36. Haranczyk M, Gutowski M, Li X, Bowen KH (2007) Adiabatically bound valence anions of guanine. J Phys Chem B 111:1407314076

37. Szeląg M, Raczyńska ED (2008) Tautomeric equilibria for uric acid. Trends Org Chem 12:19-31

38. Raczyńska ED, Makowski M, Szelag M, Kamińska B, Zientara K (2010) Importance of CH Tautomers in the Tautomeric Mixture of Uric Acid. J Mol Struct (THEOCHEM) 947:83-91

39. Raczyńska ED (2012) Quantum-chemical studies of the consequences of one-electron oxidation and one-electron reduction for imidazole in the gas phase and in water. Comput Theoret Chem 993:73-79

40. Raczyńska ED, Stępniewski TM, Kolczyńska K (2011) Consequences of one-electron oxidation and one-electron reduction for aniline. J Mol Model 17:3229-3239

41. Parr RG, Yang W (1989) Density functional theory of atoms and molecular orbital theory. Oxford University Press, New York

42. Becke AD (1993) Density-functional thermochemistry. III. The role of exact exchange. J Chem Phys 98:5648-5652

43. Lee C, Yang W, Parr RG (1988) Development of the colle-salvetti correlation-energy formula into a functional of the electron density. Phys Rev B 37:785-789

44. MiertusS Tomasi J (1982) Approximate evaluation of the electrostatic free energy and internal energy changes in solution processes. Chem Phys 65:239-241

45. Miertus S, Scrocco E, Tomasi J (1981) Electrostatic interaction of a solute with a continuum. Adirect utilization of ab initio molecular potentials for the prevision of solvent effects. Chem Phys 55:117-129

46. Hehre WJ, Radom L, Schleyer PvR, Pople JA (1986) Ab initio molecular theory. Wiley, New York

47. Riestra-Kiracofe JC, Tschumper GS, Schaefer HF III, Nandi S, Ellison GB (2002) Atomic and molecular electron affinities: photoelectron experiments and theoretical computations. Chem Rev 102:231-282

48. Wetmore SD, Russell JB, Eriksson LA (2000) Electron affinities and ionization potentials of nucleotide bases. Chem Phys Lett 322:129-135

49. Walch SP (2003) Model calculations of the electron affinities and ionization potentials of DNA. Chem Phys Lett 374:496-500

50. Close DM (2004) Calculation of the ionization potentials of the DNA bases in aqueous medium. J Phys Chem A 108:10376-10379

51. Li XF, Cai ZL, Sevilla MD (2002) DFT calculations of the electron affinities of nucleic acid bases: dealing with negative electron affinities. J Phys Chem A 106:1596-1603

52. Krygowski TM (1993) Crystallographic studies of inter- and intramolecular interactions reflected in aromatic character of p-electron systems. J Chem Inf Comput Sci 33:70-78

53. Raczyńska ED, Krygowski TM, Duczmal K, Hallmann M (2006) On geometry-based HOMED (a measure of hyperconjugation, n-pi, and pi-pi conjugation) and HOMA index (a measure of aromaticity). XVIII International Conference on Physical Organic Chemistry, Warsaw (Book of abstracts, p. 31)

54. Raczyńska ED, Hallmann M, Kolczyńska K, Stẹpniewski TM (2010) On the harmonic oscillator model of electron delocalization (HOMED) index and its application to heteroatomic pi-electron systems. Symmetry 2:1485-1509

55. Frisch MJ, Trucks GW, Schlegel HB, Scuseria GE, Robb MA, Cheeseman JR, Montgomery JA Jr, Vreven T, Kudin KN, Burant JC, Millam JM, Iyengar SS, Tomasi J, Barone V, Mennucci B, Cossi M, Scalmani G, Rega N, Petersson R, Nakatsuji H, Hada M, Ehara M, Toyota K, Fukuda R, Hasegawa J, Ishida M, Nakajima T, Honda Y, Kitao O, Nakai H, Klene M, Li X, Knox JE, Hratchian HP, Cross
JB, Bakken V, Adamo C, Jaramillo R, Gomperts R, Stratmann RE, Yazyev O, Austin AJ, Cammi R, Pomelli C, Ochterski JW, Ayala PY, Morokuma K, Voth GA, Salvador P, Dannenberg JJ, Zakrzewski VG, Dapprich S, Daniels AD, Strain MC, Farkas O, Malick DK, Rabuck AD, Raghavachari K, Foresman JB, Oritz JV, Cui Q, Baboul AG, Clifford S, Cioslowski J, Stefanov BB, Liu G, Liashenko A, Piskorz P, Komaromi I, Martin RL, Fox DJ, Keith T, Al-Laham MA, Peng CY, Nanayakkara A, Challacombe M, Gill PMW, Johnson B, Chen W, Wong MW, Gonzalez C, Pople JA (2004) Gaussian-03, Revision E.01. Gaussian, Inc, Wallingford

56. Pauling L (1960) The nature of the chemical bonds, 3rd edn Cornell University Press, New York, p 564

57. Sun G, Nicklaus MC (2007) Natural resonance structures and aromaticity of the nucleobases. Theor Chem Acc 117:323-332

58. Krygowski TM, Cyrański MK (2001) Structural aspects of aromaticity. Chem Rev 101:1385-1419

59. Cyranski MK (2005) Energetic aspects of cyclic $\pi$-electron delocalization: evaluation of the methods of estimating aromatic stabilization energies. Chem Rev 105:3773-3811

60. Chen Z, Wannere CS, Corminboeuf C, Puchta R, Schleyer PvR (2005) Nucleus-independent chemical shifts (NICS) as an aromatic criterion. Chem Rev 105:3842-3888

61. Kruszewski J, Krygowski TM (1972) Definition of aromaticity basing on the harmonic oscillator model. Tetrahedron Lett 13:3839-3842

62. Krygowski TM, Oziminski WP, Cyrański MK (2012) Aromatic character of heptafulvene and its complexes with halogen atoms. J Mol Model 18:2453-2460

63. Frizzo CP, Martins MP (2012) Aromaticity in heterocycles: new HOMA index parametrization. Struct Chem 23:375-380

64. Fogarasi G (2010) Studies on tautomerism: benchmark quantum chemical calculations on formamide and formamidine. J Mol Struct 978:257-262

65. Lammertsma K, Prasad BV (1994) Imine-enamine tautomerism. J Am Chem Soc 116:642-650

66. Lin XJ, Wang Q, Wu J, Liu CB (2008) DFT study on the mechanism of DNA damage caused by the isomerization of DNA purine base. J Theoret Comput Chem 7:457-472

67. Shukla MK, Leszczynski J (2010) Comprehensive evaluation of medium and long range correlated density functionals in TD-DFT investigation of DNA bases and base pairs: gas phase and water solution study. Mol Phys 108:3131-3146

68. Shanmugasundaram M, Puranik M (2011) Vibrational markers of structural distortion in adenine nucleobase upon DNA damage. Phys Chem Chem Phys 13:3851-3862

69. Raczyńska ED, Makowski M, Zientara-Rytter K, Kolczyńska K, Stępniewski TM, Hallmann M (2013) Quantum-chemical studies on the favored and rare tautomers of neutral and redox adenine. $\mathrm{J}$ Phys Chem A 117:1548-1559

70. Krygowski TM, Kruszewski J (1974) Aromaticity of thiophene, pyrrole and furan in terms of aromaticity indices and Hammett $\rho$ constants. Bull Acad Pol Sci Sr Sci Chim 22:871-876

71. Ahn D-S, Lee S, Kim B (2004) Solvent-mediated tautomerization of purine: single to quadrupole proton transfer. Chem Phys Lett 390:384-388

72. Lias SG (http://webbook.nist.gov) Ionization energy evaluation. In NIST Chemistry WebBook, NIST Standard Reference Database Number 69. Linstrom PJ, Mallard WG (eds) National Institute of Standards and Technology, Gaithersburg MD, 20899

73. Schwell M, Jochims H-W, Baumgärtel H, Leach S (2008) VUV photophysics and dissociative photoionization of pyrimidine, purine, imidazole and benzimidazole in the $7-18 \mathrm{eV}$ photon energy range. Chem Phys 353:145-162

74. Lifschitz C, Bergmann ED, Pullman B (1967) The ionization potentials of biological purines and pyrimidines. Tetrahedron Lett 8:4583-4586

75. Hush NS, Cheung AS (1975) Ionization potentials and donor properties of nucleic acid bases and related compounds. Chem Phys Lett 34:11-13 
76. Potts AW, Holland DMP, Trofimov AB, Schirmer J, Karlsson L, Siegbahn K (2003) An experimental and theoretical study of the valence shell photoelectron spectra of purine and pyrimidine molecules. J Phys B At Mol Opt Phys 36:3129

77. Verkin BI, Sukodub LF, Yanson IK (1976) Ionization potentials of nitrogenous bases of nucleic acids. Dokl Akad Nauk SSRR 228:14521455

78. Hwang CT, Stumpf CL, Yu Y-Q, Kenttämaa HI (1999) Intrinsic acidity and redox properties of the adenine radical cation. Int J Mass Spectrom 182(183):253-259

79. Peng S, Padva A, LeBreton PR (1976) Untraviolet photoelectron studies of biological purines: the valence electronic structure of adenine. Proc Natl Acad Sci USA 73:2966-2968

80. Bartmess JE (http://webbook.nist.gov) Negative ion energetics data. In NIST Chemistry WebBook, NIST Standard Reference
Database Number 69. Linstrom PJ, Mallard WG (eds) National Institute of Standards and Technology, Gaithersburg MD, 20899

81. Desfrancois C, Abdoul-Carmine H, Schermann JP (1996) Electron attachment to isolated nucleic acid bases. J Chem Phys 104:77927794

82. Chen ECM, Chen ESD, Wentworth WE (1990) The role of electron donors and acceptors in base stacking in DNA and RNA. Biochem Biophys Res Comm 171:97-101

83. Wiley JR, Robinson JM, Ehdaie S, Chen ECM, Chen ESD, Wentworth WE (1991) The determination of absolute electron affinities of the purines and pyrimidines in DNA and RNA from reversible reduction potentials. Biochem Biophys Res Comm 180:841-845

84. Aflatooni K, Gallup GA, Burrow PD (1998) Electron attachment energies of the DNA bases. J Phys Chem 102:6205-6207 